\title{
Histopathological Effect of Varying Dose of Acetylsalicylic Acid (Aspirin) on Liver of Adult Wistar Rats
}

\author{
Idehen I Charles $^{1 *}$, Bankole J Kayode ${ }^{1}$, Airhomwanbor Kingsley ${ }^{1}$, Dic-Ijiewere Ebenezer ${ }^{2}$, \\ Okparaku Sunday $^{1}$, Ehimara Raphael ${ }^{2}$, OsaroboEseiwi ${ }^{3}$, Aigbiremolen Emmanuel ${ }^{1}$ \\ ${ }^{1}$ Department of Medical Laboratory Science, College of Medicine, Ambrose Alli University, Ekpoma, Nigeria \\ ${ }^{2}$ Department of Chemical Pathology, College of Medicine, Ambrose Alli University, Ekpoma, Nigeria \\ ${ }^{3}$ Department of Heamatology, College of Medicine, Ambrose Alli University, Ekpoma, Nigeria \\ *Corresponding Author: Idehen I Charles, Basic Medical Sciences, Department of Medical Laboratory Science, \\ College of Medicine, Ambrose Alli University, Ekpoma, Nigeria, E-mail: uwaifoha@ yahoo.co.uk
}

Received: 28 November 2018; Accepted: 10 December 2018; Published: 20 December 2018

\begin{abstract}
Aspirin is one of the widely-used, cheap and over-the-counter available non-steroidal anti-inflammatory drugs. It has anti-platelet, analgesic and anti-pyretic effects which can result in its indiscriminate ingestion. The liver is the organ of drug metabolism, bio-regulation and immuno-modulation. Thus, this study investigates the effects of varying aspirin doses on the gross and cellular architecture of the liver in Adult Wistar rat model. Thirty rats of comparable weights were divided into 5 groups; consisting of a control group and 4 tests. Group A served as control and was not treated while groups B, C, D and E served as the tests and were treated daily with 35, 70, 105 and 140 $\mathrm{mg} / \mathrm{kg}$ body weight of aspirin respectively for 30 days. At the end of the experiment, the rats were anesthetized, and the liver dissected out for gross and histological studies. There was a slight dose-dependent increase in body weight, but no noticeable gross liver change. However, there were dose dependent histo-pathological changes including sinusoidal congestion and increased cell basophilia from the $70 \mathrm{mg} / \mathrm{kg}$ to $140 \mathrm{mg} / \mathrm{kg}$ dose. Conclusively, aspirins at doses $70 \mathrm{mg} / \mathrm{kg}$ body weight and higher are associated with hepatic pathologies and care should be taken when these doses are administered for long durations.
\end{abstract}

Keywords: Aspirin; Anti-inflammatory drugs; Liver; Histology; Hepatotoxic

\section{Introduction}

Aspirin, an acetylated salicylate (acetylsalicylic acid- ASA), is classified among the non-steroidal anti-inflammatory drugs (NSAIDs) [1]. It is one of the well-known, cheap, easily available and widely used Non-Steroidal Anti 
Inflammatory Drug (NSAID). It is used in versatile purposes which include anti-inflammatory (in joint diseases), anti-platelets (in cardiovascular disease), analgesic and antipyretic [2]. Aspirin is a safe drug at low doses but also has life-threatening side effects when administered at high doses. It has also been reported to cause adverse effects in pregnancy [3]. In-vitro and in-vivo studies showed that aspirin at high doses caused necrosis of the blood vessel tissues [4]. Long-term therapeutic use of aspirin has been associated with nephrotoxicity, hepatotoxicity, gastrointestinal ulcerations, and renal cell cancer and adverse effects to multiple organ systems [5, 6]. Administration over a period of time has been documented to cause significant histopathological changes in the liver [7] that is confirmed to the cellular level [8].

ASA is metabolized via conjugation in the liver to form salicyic acid and several other metabolites which may have justified its hepatotoxic potentials. ASA disperse throughout the body after ingestion, with the highest concentrations found in the blood plasma, liver, renal cortex, heart and lungs [9]. These claims that ASA is toxic to the liver were documented over 30 years ago and thus necessary to validate these claims and possible outcomes of varying doses. It is therefore the aim of this study to investigate the effect of varying doses of aspirin on the liver histological architecture using albino Wister rats as a model.

\section{Materials and Methods}

Aspirin (containing $300 \mathrm{mg} /$ tablet acetylsalicylic acid) with trade name Emzor pharmaceutical was purchased from a pharmacy in the study area. This experimental study was conducted in the histological laboratory of Ambrose Alli University, Ekpoma- Nigeria. The rats were procured from the Animal Farm, College of Medicine, Ambrose Alli University, Ekpoma and transferred to the site of experiment where they were allowed two (2) weeks of acclimatization. A total of 30 albino Wistar rats of comparable weights ranging from 165-200 g were used. They were kept in wire mesh cages with tripod that separates the animal from its feces to prevent contamination. During the period of acclimatization, the rats were maintained in accordance with the standard guide for the care and use of Laboratory animals and fed rat chow and clean water ad libitum.

The albino Wistar rats were divided into 5 groups. Group A served as the control and groups B, C, D and E rats were administered daily dose of $35 \mathrm{mg} / \mathrm{kg}, 70 \mathrm{mg} / \mathrm{kg}, 105 \mathrm{mg} / \mathrm{kg}$ and $140 \mathrm{mg} / \mathrm{kg}$ body weight respectively. The aspirin solution was prepared daily by grinding the aspirin tablets and diluting the powder in clean water. Using $1 \mathrm{ml}$ syringe, the corresponding dose was given to each rat based on body weight. The treatment was carried out daily for 30 consecutive days. At the end of 30 days treatment, the rats were sacrificed, and the liver harvested and cleandried with blotting paper for gross examination. Thereafter, the liver was fixed in $10 \%$ Formal saline for histological processing. The classical paraffin sectioning (3-5 $\mu$ thick) was cut, stained with Haematoxylin and Eosin staining technique and observed under light microscopy for histopathological changes as previously documented in Idehen et al. [10] and micrographic pictures taken. 


\section{Result}

Figure 1 shows the mean body weight gain of rats after varying dose of aspirin treatment for 30 days.

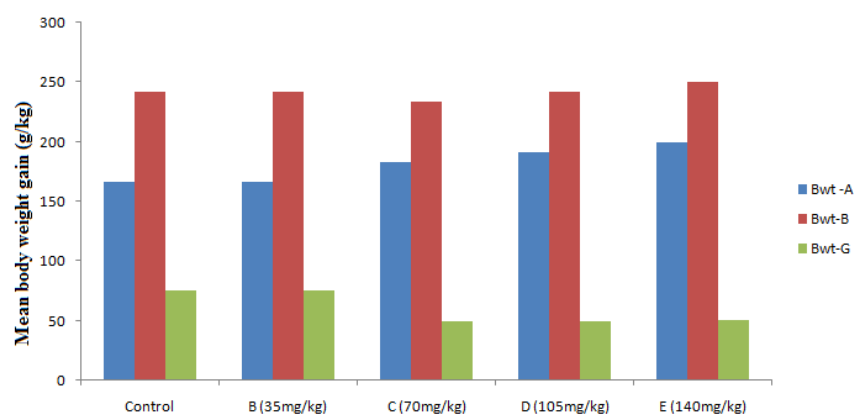

Key: Bwt-A-weight before experiment; Bwt-B-weight after experiment; Bwt-G-body weight gain; values are mean \pm standard deviation.

Figure 1: Mean body weight gain after varying dose of aspirin treatment for 30 days.

Except for the group treated with $35 \mathrm{mg} / \mathrm{kg}$ aspirin, there were decrease in body weight of the rats in group C, D and E treated with $70 \mathrm{mg} / \mathrm{kg}, 105 \mathrm{mg} / \mathrm{kg}$ and $140 \mathrm{mg} / \mathrm{kg}$ aspirin respectively compared to the control. Gross examination of the liver showed no observable alteration (Table 1).

\begin{tabular}{|l|l|l|l|l|l|}
\hline Group & Dosage of & Gross findings & \multicolumn{4}{|l|}{ Microscopic examinations } \\
\cline { 4 - 6 } & aspirin (mg) & & $\begin{array}{l}\text { Sinusoidal } \\
\text { Congestion }\end{array}$ & $\begin{array}{l}\text { Increased cell } \\
\text { Basophilia }\end{array}$ & Vacoulation \\
\hline A-Control & - & Normal & $0 / 6$ & $0 / 6$ & $0 / 6$ \\
\hline B & 35 & Normal & $0 / 6$ & $0 / 6$ & $0 / 6$ \\
\hline C & 70 & Normal & $0 / 6$ & $1 / 6$ & $2 / 6$ \\
\hline D & 105 & Normal & $0 / 6$ & $2 / 6$ & $3 / 6$ \\
\hline E & 140 & Normal & $2 / 6$ & $5 / 6$ & $4 / 6$ \\
\hline
\end{tabular}

Table 1: Gross and histological observations in the liver of rats treated with varying doses of aspirin.

However, histological observations showed normal histology of liver in group A with no observable alteration in hepatocytes (A), sinusoids (S) and central vein (V). Group B (test group treated with $35 \mathrm{mg} / \mathrm{kg}$ of aspirin) also showed no sign of any form of pathology. There were increased cell Basophilia in group C (test group treated with $70 \mathrm{mg}$ of aspirin) and D (test group treated with $105 \mathrm{mg}$ of aspirin) and the liver section of group E (test group treated with $140 \mathrm{mg}$ of aspirin) showed severely increased amount of cell basophilia and moderate sinusoidal congestion (Figure 2). 

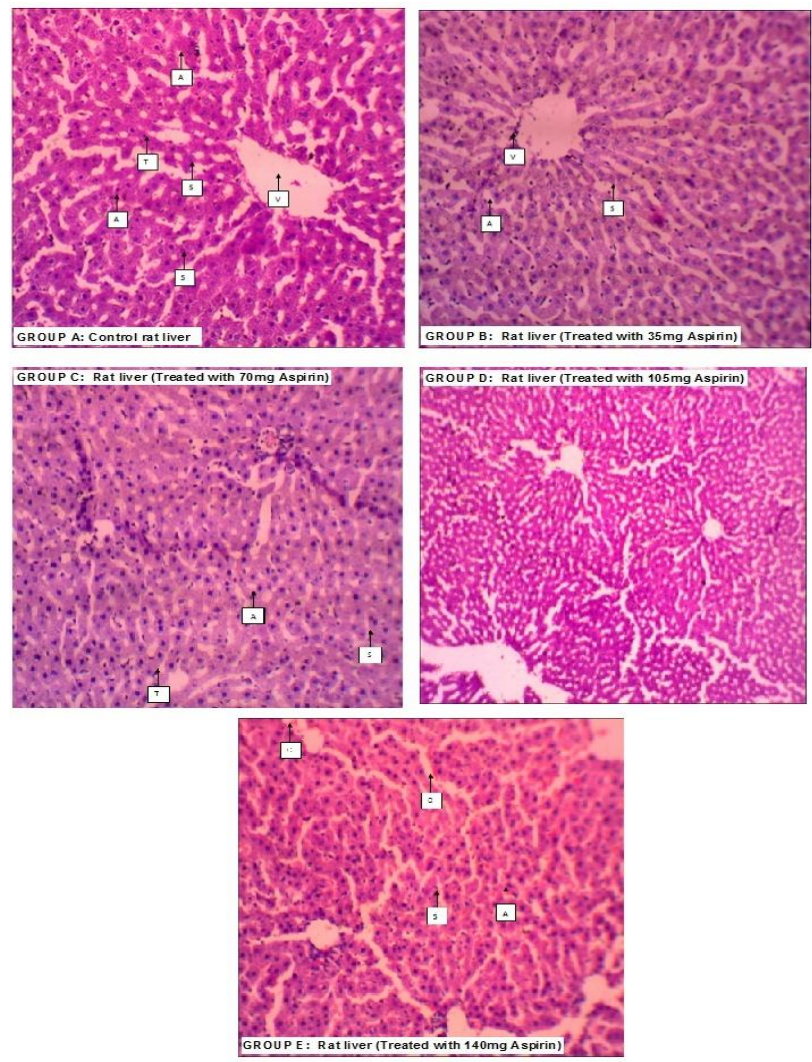

Figure 2: Histological presentations of the livers of rats treated with varying doses of aspirin compared to control

( $\mathrm{H}$ and $\mathrm{E} \times 100)$.

\section{Discussion}

In the present study, aspirin ingestions at a dose greater that $70 \mathrm{mg} / \mathrm{kg}$ resulted in decrease body weight gain, no gross alteration in the appearance of the liver but increased cell basophilia and at a dose of $140 \mathrm{mg} / \mathrm{kg}$ causes moderate sinusoidal congestion. These findings suggest that aspirin at high dose of $140 \mathrm{mg} / \mathrm{kg}$ may be hepatotoxic. In line with these findings, Mitchell et al. [7] has previously documented aspirin to cause significant histopathological changes in the liver and Rau et al. [8] reported aspirin treated rat to present liver with hepatocytes degenerative and pycknotic changes, vacuolization, clear sinusoids dilations and hypertrophied hepatocytes. In the present study, except for group B treated with $35 \mathrm{mg} / \mathrm{kg}$ aspirin that showed comparable hepatocytes histology with the control, doses from $70 \mathrm{mg} / \mathrm{kg}$ cause changes in liver histology. The non observable changes with $35 \mathrm{mg} / \mathrm{kg}$ aspirin support the fact that this dose is well tolerated by the liver. Although there has been no published work on the effect of aspirin on the liver using a dose as low as $35 \mathrm{mg} / \mathrm{kg}$, however, Kawar et al. [11], has reported doses as low as $35 \mathrm{mg}$ of soluble aspirin to cause cardio-vascular disorders especially in the Elderly.

In the present study, liver of rats treated with $70 \mathrm{mg}$ and $105 \mathrm{mg}$ of aspirin showed increased cell basophilia with rats treated with $140 \mathrm{mg} / \mathrm{kg}$ presenting moderate sinusoidal congestion and severely increased amount of cell 
basophilia. The increased cell basophilia could develop into hepatotoxicity; that is, lethal hepatocellular injury and hepatic massive micro-steatosis via mitochondrial dysfunction and lipid peroxidation mechanism resulting in marked fall of intracellular ATP and disrupt free fatty acid accumulation in liver. Sinusoidal congestion in the 140 $\mathrm{mg} / \mathrm{kg}$ treated rats may be associated with accumulation of blood in the venules of the hepatocytes, which is the result of back pressure within veins. These findings are in line with Sangeetha and Krishnakumari [12]. In the liver of rats treated with aspirin, Sherifa [13] has recorded vacuolar degeneration of tubules and Talat et al. [14], reported vacuolization, clear dilations in the sinusoids and hypertrophied hepatocytes with small and degenerating nuclei, have become fused in later part of this experiment.

\section{Conclusion}

The administration of aspirin at high dosage for 30 days can cause hepatic problems and changes in the histological architecture of the liver. It can therefore be recommended that aspirin should not be taken at extended durations than normally prescribed by the physician. Also, individuals with liver abnormality should not take aspirin except on recommendations. Policies can also be enacted to make aspirin and other NSAIDS e.g. peroxicam and acetaminopen prescription drugs as they are highly abused due to its relative availability and lack of knowledge of its mechanism of action. More research should be carried out on the effects of aspirin on other glands and organs of the body in order to give a broader view on its mechanism of action so as to help clinicians make an informed decision on any chosen health care plan.

\section{References}

1. Silverstein FE, Faich G, Goldstein JL, et al. Gastrointestinal toxicity with celecoxib vs nonsteroidal antiinflammatory drugs for osteoarthritis and rheumatoid arthritis: the CLASS study: A randomized controlled trial. Celecoxib Long-term Arthritis Safety Study. JAMA 284 (2000): 1247-1255.

2. Adnan S, Janabi Al, Ahmad M, et al. Pharmacological effects of low dose of aspirin on corpus luteum functions in mature cycling female mice. Institute of the Embryo Research and Infertility Treatment 10 (2005): 150-162.

3. Collins E, Turner G. Maternal Fetal effects of regular salicylate ingestion during pregnancy. Lancet 2 (1975): 335-339.

4. Smith SC, Blair SN, Bonow RO, et al. AHA/ACC Guidelines for Preventing Heart Attack and Death in Patients With Atherosclerotic Cardiovascular Disease: 2001 update. A statement for healthcare professionals from the American Heart Association and the American College of Cardiology. J Am Coll Cardiol 38 (2001): 1581-1583.

5. Gilman EA, Langman MJ, Cheng KK, et al. Effect of anti-inflammatory drugs on overall risk of common cancer: case-control study in general practice research database. BMJ 320 (2000):1642-1646.

6. Luigi DL, Laura G, Francesco R, et al. Aspirin, exercise and pituitary hormones. Official Journal of the American College of Sports Medicine 33 (2001): 2029-2035. 
7. Mitchell C, Garcia Rodriguez LA, Landolfi R, et al. Low-dose aspirin for the prevention of atherothrombosis. N Engl J Med 3 (1973): 2373-2383.

8. Rau Y, Farzana Y, Ghulam S. To evaluate the role of Aspirin (a NSAID) on renal parenchyma of young albino rats. Pak J Pharm Sci 21 (1989): 98-102.

9. Marcia LB. Use of aspirin in children with cardiac disease. Pediatric Pharmacotherapy 13 (2007).

10. Idehen IC, Bankole JK, Airhomwanbor K, et al. Spleen Histological Changes Following Monosodium Glutamate Ingestion in Adult Male Wistar Rat. Advances in Biomedical Sciences 2 (2017): 1-5.

11. Kawar ME, Reham EM. Salicylate hepato-toxicity in a patient with systemic lupus erythematosus: A case report. JRMS 17 (2010): 43-45.

12. Sangeetha B, Krishnakumari S. Tephrosiapurpurea (linn.) a folk medicinal plant ameliorates carbon tetrachloride induced hepatic damage in rats. Inter J Pharm Bio Sci 1 (2010): 1-10.

13. Sherifa KA. Hepatic and renal biochemical responses to the toxicological interaction between acetylsalicylic acid and diazinon in albino Rats. J Egypt Soc Toxicol 35 (2006): 1-6.

14. Talat Y, Farzana Y, Ghulam SQ. To evaluate the role of diclofenac sodium (a NSAID) on renal parenchyma of young albino rats. Pak J Pharm Sci 21 (2008): 98-102.

Citation: Idehen I Charles, Bankole J Kayode, Airhomwanbor Kingsley, Dic-Ijiewere Ebenezer, Okparaku Sunday, Ehimara Raphael, Osarobo Eseiwi, Aigbiremolen Emmanuel. Histopathological Effect of Varying Dose of Acetylsalicylic Acid (Aspirin) on Liver of Adult Wistar Rats. Journal of Biotechnology and Biomedicine 1 (2018): 028033.

This article is an open access article distributed under the terms and conditions of the

Creative Commons Attribution (CC-BY) license 4.0 